\title{
11 Ethics of mixed martial arts
}

\author{
Walter Veit and Heather Browning
}

Mixed martial arts (MMA), as a combat sport, is frequently criticized both within the academic literature and society more generally; dismissed as barbaric and inhumane. This stands in stark contrast with the booming popularity of the sport, not only among men but also increasingly women (see Weaving 2014). MMA is not new, however, with roots that stretch back far into Ancient Greece and China (see Stenius 2013; Acevedo and Cheung 2010). Indeed, Plato himself is said to have practiced martial arts in his youth, which is what earned him the name Plato, meaning 'broad-shouldered'. $\mathrm{He}$, along with Socrates and other Greek philosophers, repeatedly emphasized the need for physical education, even for those who should eventually occupy the role of philosophers within society. ${ }^{2}$ Despite this, however, MMA has received almost no contemporary philosophical attention; a glaring omission in the literature that is being remedied in this volume. What little has been written typically depicts MMA as an activity that is inherently wrong (Dixon 2015) or at least problematic (Weimer 2017; Kershnar and Kelly 2020). Contrary to these foregoing analyses, we argue that MMA is not only permissible, but an intrinsically praiseworthy and virtuous endeavor, one that is required to fully develop one's moral character. We thus argue for a return to the Hellenic recognition of an intimate connection between body and mind that is closer to the first school of thought that MacDonald (2012) so elegantly described:

There exist two competing schools of thought in defining mixed martial arts: there are those who feel that it is about honour and respect, while others think that it is about punching people in the head until they fall over.

This chapter is structured as follows: we begin by analyzing and responding to Nicholas Dixon's arguments against MMA - both his empirical criticism of MMA, and his subsequent depiction of MMA as an intrinsically immoral sport. We then offer a contrary analysis that depicts MMA as an inherently praiseworthy activity one that fosters our natural moral inclination to treat not only ourselves, but also our opponents, and ultimately humanity itself, as ends in themselves.

\section{Moral critiques of MMA}

Though MMA is now one of the most popular sports in the US, it has only recently come to gain popularity and dethrone boxing as the most popular combat sport. As the first ' $\mathrm{M}$ ' in the name indicates, MMA is a mixed sport - not in the sense of Olympic events such as decathlon in which different disciplines are alternated, but in

DOI: $10.4324 / 9781003122395-12$ 
combining multiple fighting styles such as Muay Thai (Thai boxing), Brazilian JiuJitsu, wrestling, and boxing within a single bout. These fighting styles represent the most popular subdisciplines participants train in to form the most well-rounded fighter. The largest organization in MMA is the UFC, responsible for popularizing the sport and organizing fights across the globe. In their early days, bouts were promoted as the search for 'Which martial art is the strongest?', pitting combatants of different martial arts against one another. It was the search for The Ultimate Fighter, which is still reflected in the reality TV show of the same name that helped MMA to reach popularity in the public. ${ }^{2}$ In the beginning there existed few rules and fights were hyped as a bloody and 'anything goes' free-for-all. This has led to much criticism of the sport, critics deeming it barbaric and inhumane - at worst as a breeding ground for violence and crime (Brent and Kraska 2013) - a picture that was only aided by the octagon-shaped cage the fights take place in.

The sport has evolved, however - now with a more detailed rule-set than most other combat sports, undermining the barbaric picture prevalent within the public conception. Fights usually consist of several rounds, though unlike boxing where the audience can see up to 12 rounds, MMA fights are often limited to three (or at most, five) rounds. Because moves from wrestling and Jiu-Jitsu are allowed, people can throw each other and engage in locking someone's joints - for instance in a so-called 'armbar' - or by choking them. If the fighter then sees no way out of the position, then in order to avoid injury they can end the fight by tapping on their opponent, signaling the referee to step in and call it over. Fights can also traditionally end in a knockout or technical knockout (fighter declared unable to continue) or by an opponent losing consciousness through a chokehold. Fights will continue on the ground and on the cage that separates the fighters from the crowd, both of which are relatively soft. Unlike boxing, there is no ten-second countdown. If one of the fighters falls, the fight continues, thus leading many in the public to utter disapproval. These dissenting voices, however, have become increasingly submerged as MMA events have gained widespread popularity and moved onto prime-time television. Nevertheless, some still persist - including within the philosophical community. Here, we use this opportunity to offer a response to those who try to reinstate the status of MMA as an immoral activity to be condemned and prohibited (Dixon 2015).

The first philosophical treatment of mixed martial arts has been offered only recently. ${ }^{3}$ In his 2015 paper 'A Moral Critique of Mixed Martial Arts' the philosopher Nicholas Dixon sets out to depict MMA as an inherently problematic sport. Dixon goes so far as to argue that "no amount of consent can erase its inherently problematic nature' (ibid.: 381). It is hard to read his paper without feeling the vivid disgust Dixon seems to feel towards the activity. Indeed, he states the thesis of his paper in the assertion 'the initial revulsion that many viewers of MMA experience is based on sound moral arguments' (ibid.: 365), and Dixon's own revulsion is clear throughout. But is the revulsion people feel towards other people's activities really always based in moral arguments - let alone sound ones? This seems to be an unjustifiably strong assertion.

This, of course, need not imply that intuition has to be wrong in all of these cases. There is a justified moral reason, for instance, to feel revulsion against an armed robber killing an innocent customer in a store, a baby being drowned, or an animal tortured, but care must be taken to keep a degree of objectivity in one's assessment of initial moral revulsion. We may be disgusted - almost morally repulsed - by observing 
people eating pineapple pizza, yet we know that there is no real moral reason to condemn this. ${ }^{4}$ A sound reason is required to translate this emotional response into a moral judgement, one which we argue that Dixon fails to provide.

Dixon begins by drawing on one of his earlier articles (2001), in which he likewise criticizes boxing. In it, Dixon argues that blows to the head should be prohibited since research has shown conclusive evidence regarding the negative effects of head blows to the long-term health of boxers. A substantial percentage of boxers suffer from brain damage which drastically impairs their ability to live fulfilled lives.

On the basis of the evidence of the danger of significant mental impairment, I argued on two paternalistic grounds for reforming boxing to prohibit blows to the head. First, because of the vast rewards that the most successful professional boxers can earn, and because the vast majority of boxers come from lower socioeconomic backgrounds, doubts exist about the autonomy of their decision to enter the ring. Second, even if the initial decision to join the profession is fully autonomous, brain damage diminishes fighters' future autonomy, and I can use what I call 'preemptive paternalism' to justify restricting their current freedom to protect their future ability to think rationally.

(Dixon 2015: 366)

As Dixon points out, many boxers have a drastically reduced quality of life, since the brain is involved in 'rational, autonomous decision making' (ibid.: 366) and the rate of chronic traumatic encephalopathy (CTE) is high.

The argument that the vulnerable in society might be disproportionately led to become boxers and take injuries because they could not otherwise survive seems to us somewhat weak (though it has a strong cousin in the case of poverty leading to prostitution; see Monroe 2005). Unless they become famous, fighters typically earn very little. ${ }^{5}$ They are thus more likely to be injured through their participation in frequent matches, as opposed to professional fighters who can lay off for months before their next fight. However, even if some fighters are drawn to risk themselves for money alone, this should simply lead to a call for stronger regulations - such as fighters with pre-existing injuries being barred from the ring - rather than a ban on the practice entirely.

Dixon's argument also relies on the paternalistic idea that due to brain injury, boxers will over time lose their capacity for autonomous decision-making and thus may enter into fights they would not otherwise have done if they had full autonomy at the time. This argument is more plausible as fighters are known to get 'punch-drunk' and yet continue their careers. However again, this seems more like a call for the strengthening of existing health guidelines and medical checks for fighters than for a wholesale ban on the activity. We are thus in agreement with Dixon, that if MMA leads to diminished capabilities in making informed decisions, we may ban anyone showing signs of punch-drunkenness from entering again. But such an exclusion would not prevent healthy individuals from entering fights since it takes many fights to develop the condition. If anything, it would be a call for a limit on the number of fights a fighter could have in their career. This is something we are not opposed to, but it is far from the more radical conclusions Dixon endorses.

Ultimately, Dixon doesn't rely on these arguments to make the case against MMA, as the evidence is still too sparse and currently suggests that the danger of head 
injuries is lower in MMA than in boxing. ${ }^{6}$ Indeed, the rate of injury more generally within MMA does not suggest itself to be significantly higher than in any other combat sport. ${ }^{7}$ Neither does he rely on the argument that MMA leads to violence outside the ring (either by the fighters themselves or by spurring violence in the audience). There is almost no data on these matters, so we should be careful not to draw any hasty conclusions, an attitude which Dixon himself adopts. ${ }^{8}$ His paternalistic argument is thus little more than a set-up to make us buy into his otherwise exceedingly strong thesis of the intrinsic immorality of MMA.

\section{'The intrinsic immorality of MMA'}

In arguing for what he terms the 'intrinsic immorality of MMA', Dixon (2015: 367) draws on an argument Paul Davis made about boxing:

The face of at least one boxer will suggest an attitude of unbridled ferocity toward the opponent. A snapshot of the face of a fighter on the offensive is liable to reveal an attitude toward the opponent that, in any other context, might be fairly described as vicious.

(Davis 1993: 52 in Dixon 2015)

Dixon believes the viciousness expressed in MMA is all the more pronounced as it resembles an actual street fight in which both parties could end up on the floor, using also their knees and elbows. Dixon thinks that the viciousness inherent in this type of fighting violates the Kantian respect for humans as 'ends in themselves'. We think that Dixon is mistaken here, but shall sketch out the rest of his argument before detailing our response.

According to Kant's categorical imperative, we should never treat another human as a mere means but, Dixon argues, mixed martial artists do just that. They 'treat each other as objects to be hurt and injured and not as ends in themselves' (ibid.: 367). We are all familiar with problematic cases of objectification, and Dixon mentions several:

A man treats a woman as a sex object if he regards her merely as a source of sexual gratification, without regard for her own desires or interests. Muggers treat their victims solely as objects from which to obtain money. Sycophants treat their rich acquaintances in the same way, albeit in a slightly more subtle manner. Ruthless politicians treat rivals and colleagues alike merely as stepping stones - objects to be manipulated - to their own accumulation of power. I can objectify people in one way but not in others: muggers, for instance, typically do not treat their victims as sex objects, but mugging remains a clear instance of treating people solely as means.

(Dixon 2015: 368)

What matters for Kant is whether we treat people exclusively as means. Dixon cites Martha Nussbaum (1995), who has argued as an example that there is nothing problematic in using a partner's stomach as a pillow, since the context is a loving relationship. The context is important, a point we will later return to in order to defend MMA fights. Dixon (2015), nevertheless, recognizes that even if one applies Kant's principles, we are not necessarily equipped with a 'mechanical formula that produces a definitive verdict when I supply the factual details of whatever situation is under moral 
scrutiny', rather, we are supplied with a 'framework that gives us guidance regarding the questions we should ask, and using this framework in particular cases requires analysis and argument' (ibid.: 368). Even cases that initially appear to be clear-cut can be discussed within the framework; consider for instance the death penalty.

Dixon, however, does not believe that MMA is comparable to the death penalty in this regard, and thinks it much closer to paradigm cases of objectification such as '[m]urder, rape, and robbery' (ibid.: 369). Indeed, he seems to suggest that MMA is intrinsically worse than physical assault in the context of a robbery, since here the intention to injure and hurt another person is the very goal and not just an instrumental means towards robbing the other person. ${ }^{9}$ Finally, Dixon argues that unlike our previous stomach-pillow example, there is 'no broader context of respect for the victim that would ["]cleanse["] it' (ibid.: 369). We think Dixon is mistaken in these assertions. This leaves us with two possibilities to restore the moral praiseworthiness of MMA: (i) show that mixed martial artists do not treat each other solely as means, and (ii) show that there is a broader context of respect that does indeed 'cleanse' the violence; to which we will now turn.

\section{The intrinsic praiseworthiness of MMA}

It is perhaps not a surprising event that both philosophical treatments of MMA to have come after Dixon (2015) are replies to him. Both Weimer (2017) and Kershnar and Kelly (2020) argue that MMA is not intrinsically wrong and can be a permissible activity. In this section, we will use some of their arguments to support a stronger conclusion: the intrinsic praiseworthiness of MMA. Let us therefore now address what Dixon (2015) dismisses as the possible avenues through which MMA could be found to be morally permissible after all.

Since both (i) and (ii) above rely on respect, the argument against Dixon (2015) will largely be a unified one. Both Weimer (2017) and Kershnar and Kelly (2020) recognize that mutual respect and consensual matches are possible and MMA fights should thus not be seen as intrinsically wrong. Kershnar and Kelly make this more explicit than Weimer, arguing that one can observe 'respect and warm feelings [MMA fighters] have for opponents before and after a fight', that they 'often "pull back" a punch or kick they have thrown, or release a submission hold, when they become aware that their opponent has been sufficiently subdued, sometimes before the referee declares the fight over' (ibid.: 108). ${ }^{10}$ Dixon seemingly responds to this possibility that there could be such respect in MMA, raising the point as a possible objection to his view:

Although the suggestion that the attempt to hurt and injure opponents in the cage is 'cleansed' by fighters' respectful attitude toward each other outside the cage is appealing, it cannot rescue MMA from this paper's critique. First, Nussbaum's defense of objectification in a loving relationship works because the couple's actions, including using the partner's stomach as pillow, and sex itself, are transformed by their love into acts of tenderness. Professional respect among cage fighters, in contrast, cannot transform violent acts into anything more than attempts to hurt and injure. Second, this attempt to justify MMA falls foul of Kant's injunction that we should treat other people as ends in themselves at the same time that we treat them as means.

(Dixon 2015: 376) 
Upon closer inspection of this paragraph, however, we must realize that Dixon (2015) doesn't actually provide an argument refuting the objection. He merely asserts that (a) respect among fighters cannot transform these actions, and (b) the respect occurs after the fight, not during it. The act of injuring an opponent, Dixon thinks, is thus a paradigm case of treating someone merely as a means. Since Dixon does little to support these assertions, we are supposed to take them as given, but this is surprising considering his strong conclusion that MMA is intrinsically bad. In moral philosophy there are very few acts (if any) that are considered intrinsically bad, for it suggests that there cannot ever be any context in which the practice is morally permissible, and that the intentions of the actors could not make a difference - an incredibly bold assertion.

Perhaps MMA would appear to the uninitiated as just such a paradigm case. Imagine someone who has never heard of the sport - be it a woman or a man - walking down the streets of downtown Chicago. They hear a ruckus: people screaming, cheering, and music playing. Wanting to investigate, they enter an old run-down former industrial building, in which they see a cage with two bloody humans hitting each other, while one lies on the ground. We have no doubt that the initial response to this would be shock. The person might very well think: 'What is going on here?' or 'This cannot be legal!'. But as discussed earlier, we should be careful not to use such 'instinctive' moral revulsion as guidance. People used to hold similar emotional reactions to homosexuality, BDSM, interracial marriage (some unfortunately still do). We should be careful not to give in to the temptation of seeing acts and practices we are unfamiliar with - and that may even appear strange to us - as something that must be morally bad. Consider the quote from James MacDonald (2012) in the epigraph:

There exist two competing schools of thought in defining mixed martial arts: there are those who feel that it is about honour and respect, while others think that it is about punching people in the head until they fall over.

(MacDonald 2012)

We should now try to overcome this strict black and white dichotomy in the debate. Both Weimer (2017) and Kershnar and Kelly (2020) ultimately argue that it is the consent among the participants in MMA matches that renders them permissible. We agree with this line of thought, though will not pursue that line here. Instead, we will argue that the respect found in MMA suggests not merely that MMA is not intrinsically bad, but rather the stronger claim that it makes MMA intrinsically good. Let us therefore further examine the respect present within MMA.

\section{Respect, means, and ends in MMA}

Respect is an integral part of MMA, a message that every MMA organization is trying hard to convey to the general public. While the UFC is the biggest MMA organization in the world, there exist numerous smaller ones, such as the German RFC, which is short for: Respect Fighting Championship. Fighters frequently pay tribute to their opponents after a fight, praising them and acknowledging their feats. Even fighters that bad-mouthed each other and were seemingly out to kill each other in the ring are often seen hugging each other after a fight. To Dixon, this is not important since despite mutual consent the fighters still violate each others' bodies in 
fighting, and thus he argues they treat each other merely as means. This, we think, gets Kant backwards. It is instead those that do not engage in MMA fights that treat themselves as mere means. Let us elaborate.

Kerstein, in her article titled 'Treating Oneself Merely as a Means', argues that Kant recognizes six duties to oneself: the duty not to kill oneself, a duty not to lie, a duty not to treat oneself as a mere means for lust (e.g., masturbation), a duty not to become a destroyer of the beautiful, a duty not to be cruel to animals, and a duty to 'recognize all our duties as divine commands' (2008: 201). Kant's list is an odd one, and Kant scholars have done much to make his account more coherent. Kerstein (ibid.), for instance, points to an apparent oddity that our duty to treat other animals without cruelty is a perfect duty to ourselves, while our obligations to other humans are duties to them. Kant argues that poor treatment of animals 'dulls [man's] shared feeling of their suffering and so weakens and gradually uproots a natural predisposition that is very serviceable to morality in one's relationship with other people' (Kant 1996: 443).

This concept - of perfect duties to ourselves - provides the lens through which to see the intrinsic praiseworthiness of MMA. While Kant argued for an imperfect duty to develop our talents, this is not the line of argument we will pursue to defend MMA, though it is of course applicable. We take a stronger line - that fighting in mixed martial arts bouts is itself an instance of a perfect duty to oneself. To omit this kind of engagement inherent to perfect duties would as Kerstein argues, involve 'a failure to give humanity, namely one's own, the respect it demands' - a failure to treat oneself as a rational agent (2008: 207). It is one that must be followed and allows no degree of flexibility, since it gradually strengthens our natural inclination to see our own bodies as ends in themselves, something that (like positive treatment of animals) is serviceable to morality in one's relationship to oneself and other people. To respond to an inevitable criticism of this position, we are not arguing that every human is required to become a professional MMA fighter - no less as our perfect duty to other animals requires everyone to become a professional animal rights activist or animal welfare researcher (though these are undeniably virtuous activities). The activity may be praiseworthy without being obligatory. Rather, the key here is the development of one's moral character.

A similar but distinct objection would be to hold that while there is something special, perhaps even intrinsically so, about this form of fighting, there are numerous other intrinsic goods that require time and effort and would have to be sacrificed for MMA. But here the same reply applies - unless it is necessary to practice MMA daily to develop one's moral character (which we do not hold) it is less clear how it would stand in the way of other goods. It is true that there is a plurality of moral goods, but as with Aristotle we may simply recognize that we have to accept that there will be some trade-offs and the trick will be to find the 'golden middle' so to speak.

Importantly, this position is not any bolder than Dixon's argument that MMA is somehow intrinsically immoral, since it merely involves a special development, a special 'coming to terms with' what it means to be a human. We recognize that this is nevertheless a strong position to hold, but it will become more plausible once it is recognized that there is no self, no personal identity, without a physical body. It is frequently acknowledged in the literature that Kant has failed to recognize our embodied nature (Svare 2006): that our identity is physical rather than merely mental. Even our minds are part of this embodied nature of selves, something that was 
commonly understood in Ancient Greek but lost in the modern world that embraced a mind-body dualism (Reid 2010).

When, as Green points out, MMA fighters report to seek out the sport in order to feel alive - to feel their body - it is a recognition that there is more to MMA than other sports. $^{11}$ It is a bodily experience that goes beyond what has been described as the experience of 'flow' or 'being in the zone' (Green 2011: 392). Unlike most sports, fighting involves a special sort of pain that is directly inflicted on oneself by others. Green suggests, that pain "not only helps build confidence that something "real" is happening, but that pain also leads to an inward movement that cuts through preoccupations leading to what participants describe as the discovery' (ibid.: 391) of identity or selfhood. Unlike other sports where the individual 'dissolves' and becomes one with the environment (e.g., rock climbing or parkour) or a team (e.g. soccer), in fighting this phenomenon is reversed. There is a sort of reverse pull towards oneself. It is a felt motion that Green argues that one is 'left alone, a united, feeling organism' (ibid.: 388). MMA uniquely connects one to their own body, causing a unique awareness of a body's capabilities and vulnerabilities.

This feeling is unparalleled in other sports, but may be approximated in other 'blood sports' and real street fights. However, as we will examine further at the end of the chapter, street fights often lack something that MMA possesses: a sense of greatness. In a different paper, Dixon recognizes that the 'concept of athletic superiority... includes not only physical prowess but also mental attributes' (1999: 24). There is no sport in which one could show more superior physical and mental prowess than in MMA. In an anime series about mixed martial arts this is made explicit: 'If one is born as a male, at least once in his life, he'll dream of becoming the strongest man alive'. ${ }^{12}$ Reinforcing this, fighters in the UFC frequently state that they participate because they want to be the best.

Ancient philosophers praised the physical as an integral part of education, some even recommending or practicing the ancient Greek sport of pankration, a sport that closely resembles modern MMA but was less restrictive. ${ }^{13}$ Those who do not engage in MMA can never gain the full understanding and respect for their own corporal existence. They treat their body purely as a means to other ends, while MMA fighters engage in the pursuit of mental and physical prowess and greatness for its own sake. ${ }^{14}$ True martial art is about respecting one's body as an end in itself - it is a learned recognition for seeing the self as identical to one's body. Training and fighting gradually strengthens our natural inclination to see our bodies as ends in themselves, something that is ultimately serviceable to morality in one's relationship to oneself and other people. Indeed, the very activity is a duty towards one's own corporeality:

Martial arts... ultimately, no matter what type it is, the objective is how to efficiently destroy your opponents. After that, it just depends on the heart of the fighter. If it is used for your selfish gains, then it becomes 'violence'. But if you use it to help yourself, to protect someone in need, then even a killing technique can ascend into true martial arts.

(Furinji 2014)

It is thus no problem that MMA necessarily includes violence as Dixon would have it. The respect in MMA has two targets. On the one hand, it is one's opponent that is treated with respect. When two fighters spend months to prepare their minds and 
bodies to be in their best possible shape, it would be disrespectful not to go all out against one another - indeed, it would defeat the very purpose of the activity. Some fighters may need to scream and insult their opponent in order to give $100 \%$ in the ring, but rather than a sign of disrespect, this is a part of giving respect by engaging entirely.

One possible objection to our argument here is that Dixon emphasizes that professional fighters are not in it for the pain, rather, they aim to minimize the damage they receive and maximize the damage they deal, and thus get paid. This is dissimilar to those engaged in BDSM where pain becomes in a sense transformed through an intrinsic appreciation for the sensation. ${ }^{15}$ Those active in the practice do not seek violence for its own sake. It doesn't share the apparent barbaric spirit of MMA because it is merely part of a larger appreciative and consensual act. But as we have argued throughout this section, there is no reason to think that the violence in MMA cannot be similarly transformed. Whereas Dixon places MMA at the extreme of a continuum of increasingly problematic practices such as unequal sexual relations and dwarf tossing, we shall argue that MMA is a deeply equalizing practice. Indeed, by drawing on feminist scholarship we shall show that such a transformation is one of the core features of MMA.

\section{Masculinity, gender-norms, and feminism}

The argument thus far may evoke some traditional and misogynistic stereotypes about males. Think of statements such as: 'A true man needs to be able to fight and protect his loved ones' or 'If you're too scared to fight - you're no man'. However, this is far from how we intend our argument be interpreted; rather it applies across the gender spectrum. MMA is importantly not an exclusively male sport and more and more women have joined the sport over the years, challenging traditional gender-norms surrounding fighting. In a small study, Velija et al. (2013) report that female MMA fighters feel empowered by engaging in 'blood sports' that are traditionally considered male. Yet, Velija et al. also report a sense of biological de-powerment in the sense that female MMA fighters realize their power differential to males - even at their peak, female fighters are typically out-performed by males. Nevertheless, women who practice MMA are able to reach their peak levels of both physical and mental resilience, traits that have often been thought of only as male. Indeed, former UFC champion Ronda Rousey ${ }^{16}$ argues that female fights are even more impressive in this regard, as they 'have something to prove. They're not in there to win matches. They're in there to make a point. The point is that they deserve to be in there' (2013: 50). Nancy HogsheadMakar, the Senior Director of Advocacy at the Women's Sport Foundation, similarly argues that the 'participation in combat sports in particular helps break down stereotypes that hold women back' (ibid.: 48).

Within only a few years, UFC president Dana White changed his mind from never expecting women to fight in the UFC to now - largely thanks to Ronda Rousey allowing multiple weight classes for women (see Gregory 2013). When female fighters clash, the percentage of females in the viewing audience can reach more than one third of total views, a result that is perhaps surprising since the sport is often depicted as the man's sport (Weaving 2014). Unlike the female competitions within many other sports, female fighters are thriving surprisingly well, drawing both male and female audiences. Indeed, we think for these reasons that MMA is an intrinsically feminist competition. 
Two statements of female MMA fighters recorded by Velija et al. stand out in particular: ${ }^{17}$

When asked how it felt the first time she hit someone, Emma (Kick Boxing and Thai Boxing) expressed that, 'it was brilliant, you don't realise your own strength till you do it, it's quite a good feeling you feel quite alive'. Similarly, Louise, also explains her first experience of hitting someone, 'it made me feel powerful, because you are exerting a force over someone, it's your force on them' (Louise, Kick Boxing).

(Velija et al. 2013: 530)

Again, we see the notion that MMA makes one feel alive. It is not, as Green (2011) seems to suggest, a phenomenon that applies exclusively to (rich and white) males. It is a natural inclination that is a duty to oneself. This might seem strong, but it is perhaps best illustrated as the inverse to Kant's duty to oneself in not committing suicide. An MMA fighter doesn't seek to injure his body for its own sake or to seek death. Quite the opposite: it's a phenomenological - indeed transformative - experience that leads fighters to gain an appreciation of their own embodied nature and that of others. Here, a phenomenological viewpoint in the tradition of Merleau-Ponty $(1962,1983)$ is a useful one. For Merleau-Ponty, it is the body and our sensory experience that anchors one's conscious experience, as a fundamentally embodied experience. Female MMA fighters undergo a transformative experience that in a sense 'masculinizes' their bodies and minds since fighting has been traditionally associated with manliness and masculinity. It helps to dissemble traditional gender categorizations. The phenomenological experience of hitting a taller, more muscular, and scary looking man in the face is something that empowers women. Again, unlike most other sports, MMA is special in that it enables women to experience equality to men. It is a transformative experience that cannot be gained by, say, outrunning or outlifting a male athlete.

Female fighters challenge traditional gender-norms and thus contribute to a more feminist society in which people are seen as equals. Women are no longer merely objects on which men can exert force and their will; here they become equals, as subjects able to exert force themselves. Weaving (2014), for instance, argues that MMA enables female fighters to overcome the gendered view of the female body as a mere body-object, and instead to become a body-subject, like males. It moreover challenges men to see women as subjects - individuals that pursue greatness and show strength of will - rather than mere objects subject to be dominated by the 'will of men'. Pain is the universal trait that can bring humans together and develop a shared sense of 'brotherhood' or, as we can see in female MMA, collegiality in a more general sense. Physical violence is thus transformed through the context of a fight between two equals (in the Kantian sense of a subject and end in itself) into an act of respect. The blood that flows is no longer an act of mere violence, but a true sign of our equal status as human beings. As Sun-Ken Rock says in the Japanese martial arts manga of the same name, 'In this world, the only thing we truly own is the body we shape every day' (Boichi 2012). Shaping our bodies, using them, and bringing them into contact with others is not treating ourselves or others as instrumental, but treating them as ends.

MMA is the ultimate form of competition. Consider the following statement by Forrest Griffin, former UFC Light Heavyweight Champion, and one of the few athletes to make it into the UFC Hall of Fame: 
A lot of people ask me why I fight, and the answer is pretty simple: I see mixed martial arts as the ultimate form of competition. If you're a hockey or football buff, you might disagree with me. After all, both sports are competitive and oftentimes violent. But what do the players from either sport do when they can't settle a dispute on the field? They don't challenge the person they have a problem with to a race or a goal-shooting contest. No, they rip off their gear and throw down. Why? Because fighting is the ultimate form of competition. If you get beat in Ping-Pong or darts or basketball, you can always save face by saying, 'Well, I could still kick his ass'. If you lose in fighting, you simply got beat. Never once will you hear a fighter say, 'He might have beat me in the cage, but I would slaughter him in shuffleboard'.

(Griffin 2009: 93-4)

Competition is often seen as something male - indeed, often negatively so. But it need not be. By competing, women can likewise strengthen their natural inclination to see our bodies as ends in themselves, as equal to the male body, something that is ultimately serviceable to morality in one's relationship to oneself and other people. The apparent lack of rules, the closeness to a 'real fight' is what makes the subjective experience of MMA unique and thus different from other blood sports such as boxing.

This line of argument invites a possible objection, however, that Dixon might raise: if MMA is morally superior to all other blood sports, due to its closeness to real fights, then why not go a step further and engage in actual street fights? Our response to this objection will occupy us for the rest of this chapter.

\section{Objection: why not street fights?}

If you take four street corners, and on one they are playing baseball, on another they are playing basketball and on the other, street hockey. On the fourth corner, a fight breaks out. Where does the crowd go? They all go to the fight.

(Max Kellerman, boxing analyst, as quoted by Dana White in Kantowski 2007)

If our argument succeeds, it gives rise to a natural objection - why not go further? Why is fighting within the confines of the rules of MMA the best way of experiencing this unique inhabiting of our own body? Shouldn't we instead loosen the rules of MMA to allow for bites, eye-gouging, and other techniques that are currently forbidden if they would make MMA matches even more realistic? Or, better yet, simply engage in no-holds-barred street fighting? Though we recognize this as a legitimate challenge to the argument we present here, we take it to be ultimately unsuccessful. Our response to this objection is threefold.

Firstly, there is the issue of consent. Many (if not most) fights outside a ring or octagon lack consent, or if there is consent it is often a diminished consent that we would not wish to describe as informed consent. Take, for instance, the common occurrence of two drunk guys in a bar that decide to settle a dispute by fighting it out. We may very well recognize that this is not an informed choice, and indeed here one may disrespect both one's own sober desires and the will of the other. Kant's Categorical Imperative can be interpreted as the requirement not to follow a maxim (i.e., a universalized rule) that others could not consent to (O’Neill 1989). Thus if one were to 
engage in a drunk bar fight, one might need to formalize a general maxim that all such fights are permissible, which it seems is not a rule we can universally consent to. Even if some form of consent has been given, it may not be the consent we are interested in (i.e., the informed consent of rational agents). Even in cases of complete sobriety, too many street fights are either undertaken without the will of one of the participants, or without full understanding of the potential range of actions and results. MMA fights, on the other hand, are undertaken within a controlled context in which there can be full understanding of the intentions and outcomes and thus true consent.

Secondly, it is clear that most of these street fights are not fought in a context of mutual respect. Indeed, it is plausible to think that a large majority of such fights start with mutual disrespect, such as by an insult, be it an actual or merely perceived one. These fights rarely if ever occur under a specified set of rules that both agreed to. ${ }^{18}$ Indeed, what starts as a fist-fight can often turn into an unfair fight in which one of the combatants uses a weapon such as a knife, chair, or worse a gun. In any case where a fight is decided through such means, it cannot be thought of as an embodied experience. Instead, both fighters would experience what Green (2011) may describe, as a pull outside of one's body. Rather than fostering one's natural inclinations, the use of weapons - such as the press of a button in order to kill people via a drone strike seems to actively damage one's inclination to treat oneself and others as ends in themselves. MMA fights, on the other hand, as both Weimer (2017) and Kershnar and Kelly (2020) argue, take place in a context of respect that can transform the activity Dixon characterizes as intrinsically immoral.

Third, as we discussed earlier, MMA possesses a sense of greatness that street fights lack. In fact, here we are reversing the argument that the 'naturalness' of street fights is somehow purer and thus superior to MMA fights, a feature that for instance led the Spartans to avoid Olympic pankration matches. ${ }^{19}$ True martial arts is about mental and physical prowess and greatness. This feature is lost in a so-called 'true' street fight, that rarely occurs between combatants in either peak physical or mental condition. But more importantly, unlike MMA fights that occur in an octagon with a more or less softened ground, street fights occur in an extraordinary variety of external conditions. These can include hard concrete floors, weapons, and other environmental conditions that can put the fighters at a disadvantage that has nothing to do with their mental and physical prowess. Think of the plot of the movie Million Dollar Baby in which the protagonist, a female boxer, dominates her opponent, who eventually cheats in return and gives her a sucker-punch to the back of her head. She falls and lands on a misplaced chair, breaking her neck and becoming a quadriplegic. Here, we can see two failures of the supposed purity of street fights. On the one hand, one fighter uses dirty techniques as a result of their own mental and physical inferiority, something that is akin to bringing a knife to a fist-fight, while on the other hand, an environmental condition fatally injures the greater fighter.

The intrinsic praiseworthiness of MMA comes from its ability to foster our natural inclination to see our bodies as ends in themselves, something that we become painfully aware of in the context of an institutional MMA match. True martial art is about respecting and experiencing human bodies as ends in themselves. It tells us something about what Greg Downey (2014) describes as the very 'nature of human life' though he has doubts that MMA is as realistic as many would like it to be (ibid.: 25). Most street fights, after all, directly undermine the conditions we have determined to be 
important for the moral praiseworthiness of MMA since they diminish rather than foster our natural inclination to develop our moral sense. Underground fight clubs fail for similar reasons when their sole purpose is to receive money.

Nevertheless, the rules of MMA are not fixed. The rules have changed over the years to make it safer and more appealing to general audiences. If consent and respect can be ensured within an institutional setting, we may very well recognize that a loosening of some rules is in order. Indeed, and this we will have to grant: if say two professional MMA fighters meet in a bar and both decide to engage in a fair street fight than we see no reason to morally condemn this. ${ }^{20}$ There might very well be other reasons to prohibit this practice as it will likely lead to a lot of fights that are, in fact, not fought under such conditions (whether fair conditions obtained would be difficult to assess after the fact). But this doesn't imply that the fight itself is morally wrong - this is an instrumental, rather than an intrinsic problem with the practice. It could equally lead to the strengthening of our natural inclination to see our bodies as ends in themselves, something that is ultimately serviceable to morality in one's relationship to oneself and other people. Yet, aren't underground fight clubs or street fights the 'real deal'? Isn't MMA just a show designed to facilitate hyper-real spectacles? Are these fights not merely there to entertain an audience and give them what they believe or want to think a real fight looks like? We do not hold this view since there is a big difference between the theatrical performances of professional wrestling and two fighters who try to beat each other with any available techniques and skills to prove who is the better fighter. But it need not be black-andwhite. Perhaps MMA lies on a continuum somewhere between a 'real' underground match and a scripted performance. If this is the case, we'd be willing to bite the bullet and accept the conclusion that true MMA is only found in the Untergrund. Since this issue is largely empirical and raises its own challenges unrelated to institutionalized MMA matches, we will leave this issue unsettled here. It is nevertheless an interesting one that should be explored in future work.

\section{Conclusion}

Mixed martial arts have been admired since the Ancient Greeks. Zeus himself, according to the mythos, grappled with his own father in order to rule Mt. Olympus (see Gross 2016). Gross argues that mortals could themselves become 'godlike if they found success' in the ancient Olympic games (ibid.: 20) Myths aside, the present chapter aims to show that engaging in MMA fights is far from an intrinsically immoral activity, an act of violence that fails to respect other people as ends in themselves. It is instead a virtuous and praiseworthy activity that fosters our natural inclination to see our bodies as ends in themselves, something that is ultimately serviceable to morality in one's relationship to oneself and other people. In order to realize these ends, we will have to change the negative public perception of these events. Indeed, studies have shown that the typical viewers of such fights are 'far from the sadistic spectators represented in mainstream media reports on fight pages' (Wood 2018: 36).

There is, indeed, something 'god-like' in MMA fights, in seeing two people face off in their struggle to become the best, the strongest, and most skilled. Unlike any other sport, MMA requires fighters to stay mentally alert at all times, to endure pain and nevertheless calculate their best moves in every situation. Here, MMA is more demanding than in any other fighting competition, requiring fighters to anticipate a wider range of possible techniques than any other sport. The unparalleled physical 
and mental challenges of MMA make it unique as an activity that promotes one's connection to one's own body and thus to truly treat oneself as an end rather than merely a means. This activity, like no other, fosters our natural moral inclination to treat not only ourselves, but also our opponents, and ultimately humanity itself, as an end in itself. It is for this reason that MMA is not only (contrary to Dixon 2015) a permissible activity, but one which is morally praiseworthy.

\section{Notes}

1 See Notopoulos (1939).

2 The show is the fighting equivalent of America's Next Top Model.

3 There have however been previous similar treatments of the ethics of boxing (Herrera 2002; Schneider et al. 2001; Davis 1993).

4 Some Italians may object.

5 Griffin with Krauss (2009).

6 While initially claiming that he is not making any empirical judgements, Dixon (2015) suggests that MMA is more problematic than professional boxing partially because there is no 'count' once a fighter has been downed. In actuality, the lower number of head injuries in MMA Dixon himself cites, are the very result of the lack of a down count in MMA. In the case a fighter is not able to defend themselves from a barrage of strikes after being knocked down, the referee will jump in and instantly end the fight. This is why knock-downs in MMA result in a win. In boxing on the other hand, a fighter is given 10 seconds to stand up, after which he has to live through a barrage of strikes with a brain that has already sustained substantial damage. What is dismissed as a brutal street-fighter mentality that has no place in a serious sport is thus upon closer inspection an actual safety precaution.

7 See Ngai et al. (2008).

8 The paternalistic version of Dixon's argument is discussed in more detail in another chapter of this volume.

9 In his paper, Dixon (2015) does not seek to make any policy recommendations regarding the legal status of MMA. After all, there might be many behaviors we deem immoral yet do not think require legal action: consider for instance someone lying to their partner or someone using their right to protest to advocate for the unequal treatment of different racial groups. Nevertheless, if someone were to succeed in making a case for the intrinsic immorality of MMA, then it seems justified to conclude that it should be prohibited.

10 Here citing the UFC fighter Mark Hunt as an example (Kershnar and Kelly 2020: 108).

11 Here, Green (2011) notes that in particular it is more affluent men who have searched to engage in extreme sports to feel alive again; see Le Breton (2000).

12 Titled: Grappler Baki.

13 See Russell (2004).

14 A weaker version of the argument we present here, may treat other physical activities, such as rock-climbing, as somewhere on a continuum.

15 We thank our editors for emphasizing this nuance in Dixon's argument.

16 The first female champion in the UFC.

17 While Velija et al. (2013) only interview 11 fighters, and one may thus consider the study non-representative, one should not underestimate the evidential support that can be gained through anecdotes, especially when they all point in one direction (see Browning 2017).

18 Though this may be possible if one considers, for instance, the bygone practice of dueling, which proceeded according to a strict set of rules (though often included weapons).

19 See Russell (2004).

20 Under the assumption that neither is compromised by the influence of alcohol.

\section{References}

Acevedo, W. and Cheung, M. (2010) 'A Historical Overview of Mixed Martial Arts in China', Journal of Asian Martial Arts 19(3): 30-45. 
Boichi (2012) Sun-Ken Rock (Vol. 8), Tokyo: Young King.

Brent, J. J. and Kraska, P. B. (2013) "Fighting is the Most Real and Honest Thing": Violence and the Civilization/Barbarism Dialectic', British Journal of Criminology, 53(3): 357-377.

Browning, H. (2017) 'Anecdotes Can Be Evidence Too', Animal Sentience: An Interdisciplinary Journal on Animal Feeling, 16(13), https://www.wellbeingintlstudiesrepository.org/cgi/view content.cgi? article $=1246 \&$ context $=$ animsent, accessed 17 November 2020.

Davis, P. (1993) 'Ethical Issues in Boxing', Journal of the Philosophy of Sport 20(1): 48-63.

Dixon, N. (1999) 'On Winning and Athletic Superiority', Journal of the Philosophy of Sport, 26 (1): $10-26$.

Dixon, N. (2001) 'Boxing, Paternalism, and Legal Moralism', Social Theory and Practice, 27(2): $323-344$.

Dixon, N. (2015) 'A Moral Critique of Mixed Martial Arts', Public Affairs Quarterly, 29(4): 365-384.

Downey, G. (2014) ““As Real as It Gets!” Producing Hyperviolence in Mixed Martial Arts', JOMEC Journal, 5: 1-28.

Furinji, H. (2014) Kenichi: The Mightiest Disciple (Vol. 3), S. Matsuena (trans.), Tokyo: Shonen Sunday Comics.

Green, K. (2011) 'It Hurts So It Is Real: Sensing the Seduction of Mixed Martial Arts', Social \& Cultural Geography, 12(4): 377-396.

Gregory, S. (2013) 'Women in Combat: Ronda Rousey Kicks Female Fighters into Mixed Martial Arts', Time Magazine, 25 February, 48-50.

Griffin, F., with Krauss, E. (2009) Got Fight! The 50 Zen Principles of Hand-to-Face Combat, New York: HarperCollins.

Gross, J. (2016) Ali vs. Inoki: The Forgotten Fight That Inspired Mixed Martial Arts and Launched Sports Entertainment, New York: BenBella Books.

Herrera, C. D. (2002) 'The Moral Controversy over Boxing Reform', Journal of the Philosophy of Sport 29(2): 163-173.

Kant, I. (1996) Immanuel Kant: Practical Philosophy, Cambridge: Cambridge University Press.

Kantowski, R. (2007) 'Q+A: Lorenzo Fertitta \& Dana White', Las Vegas Sun, 21 April, https:// lasvegassun.com/news/2007/apr/21/qa-lorenzo-fertitta-dana-white/, accessed 17 November 2020.

Kershnar, S. and Kelly, R. (2020) 'Rights and Consent in Mixed Martial Arts', Journal of the Philosophy of Sport, 47(1): 105-120.

Kerstein, S. J. (2008) 'Treating Oneself Merely as a Means', in M. Betzlerr (ed.), Kant's Ethics of Virtue, New York: de Gruyter, pp. 201-218.

Le Breton, D. (2000) 'Playing Symbolically with Death in Extreme Sports', Body \& Society, 6 (1): $1-11$.

MacDonald, J. (2012) 'MMA: Are Honor and Respect Just Empty Buzzwords in Today's MMA World?', Bleacher Report, 3 October, https://bleacherreport.com/articles/1357469-mma-arehonour-and-respect-just-empty-buzzwords-in-todays-mma-world, accessed 17 November 2020.

Merleau-Ponty, M. (1962) Phenomenology of Perception, New York: Routledge.

Merleau-Ponty, M. (1983) The Structure of Behavior, A. Fisher (trans.), Pittsburgh: Duquesne University Press.

Monroe, J. (2005) 'Women in Street Prostitution: The Result of Poverty and the Brunt of Inequity', Journal of Poverty, 9(3): 69-88.

Ngai, K. M., Levy, F., and Hsu E. B. (2008) 'Injury Trends in Sanctioned Mixed Martial Arts Competition: A 5-year Review from 2002 to 2007', British Journal of Sports Medicine, 42(8): 686-689.

Notopoulos, J. A. (1939) 'The Name of Plato', Classical Philology, 34(2): 135-145.

Nussbaum, M. C. (1995) 'Objectification', Philosophy \& Public Affairs 24(4): 249-291. 
O’Neill, O. (1989) Constructions of Reason: Explorations of Kant's Practical Philosophy, Cambridge: Cambridge University Press.

Reid, H. (2010) 'Aristotle's Pentathlete', Sport, Ethics and Philosophy, 4(2): 183-194.

Russell, B. (2004) History of Western Philosophy, New York: Routledge.

Schneider, A. and Butcher, R. (2001) 'Ethics, Sport, and Boxing', in W. Morgan, K. Meier, and A. Schneider (eds.), Ethics in Sport, Leeds: Human Kinetics, pp. 357-369.

Stenius, M. (2013) 'The Legacy of Pankration: Mixed Martial Arts and the Posthuman Revival of a Fighting Culture', The International Journal of Combat Martial Arts and Sciences, 13(5): 40-57.

Svare, H. (2006) Body and Practice in Kant, New York: Springer.

Velija, P., Mierzwinski, M., and Fortune, L. (2013) “'It Made Me Feel Powerful”: Women's Gendered Embodiment and Physical Empowerment in the Martial Arts', Leisure Studies, 32 (5): 524-541.

Weaving, C. (2014) 'Cage Fighting Like a Girl: Exploring Gender Constructions in the Ultimate Fighting Championship (UFC)', Journal of the Philosophy of Sport, 41(1): 129-142.

Weimer, S. (2017) 'On the Alleged Intrinsic Immorality of Mixed Martial Arts', Journal of the Philosophy of Sport, 44 (2): 258-275.

Wood, M. A. (2018) "II Just Wanna See Someone Get Knocked the Fuck Out": Spectating Affray on Facebook Fight Pages', Crime, Media, Culture, 14(1): 3-40. 